\title{
Heterochromia Iridis in Congenital Horner's Syndrome
}

\author{
Dimitri Renard $^{a}$ Luc Jeanjean $^{b}$ Pierre Labauge $^{a}$ \\ Departments of a Neurology and ${ }^{b}$ Ophthalmology, CHU Nîmes, Hôpital Caremeau, Nîmes, France
}

A 35-year-old man, followed due to idiopathic generalized epilepsy, presented heterochromia (eyes of two different colours), together with anisocoria (condition in which the left pupil is smaller than the right pupil). The anisocoria became more pronounced in the dark. The patient reported that his eyes had been of different colours ever since he could remember. A diagnosis of idiopathic congenital left-sided Horner's syndrome was made.

Heterochromia may be found in different conditions, including Sturge-Weber, Waardenburg and Parry-Romberg syndromes, ocular trauma, Fuchs' heterochromic iridocyclitis, and congenital and acquired Horner's syndrome. A unilateral lack of sympathetic stimulation during childhood interferes with the melanin pigmentation of the melanocytes in the iris, resulting in heterochromia $[1,2]$.

\section{References}

1 Imesch PD, Wallow IH, Albert DM: The color of the human eye: a review of morphologic correlates and some conditions that affect iridial pigmentation. Surv Ophthalmol 1997;41:S117-S123.

2 Gladstone RM: Development and significance of heterochromia of the iris. Ann Neurol 1969;21:184-191.

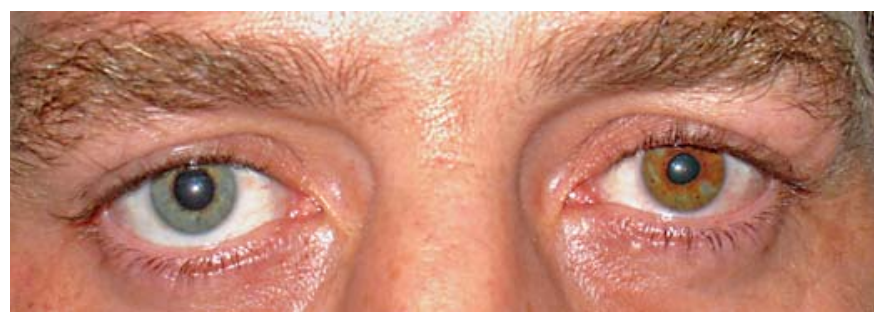

Fig. 1. The photo, taken in the dark using a flash, of the patient's eyes shows a blue iris on the right and a brown iris on the left side, together with anisocoria (left pupil smaller than the right pupil) and slight left-sided irregular pupil cycling. This is consistent with left-sided Horner's syndrome.
Dimitri Renard, MD

Department of Neurology, CHU Nîmes, Hôpital Caremeau

Place du Professeur-Debré

FR-30029 Nîmes Cedex 4 (France)

Tel. +33466 6832 61, Fax +334666840 16, E-Mail dimitrirenard@ hotmail.com 